Tree species identity influences the vertical distribution of labile and recalcitrant carbon in a temperate deciduous forest soil

Ahmed, I.U.; Smith, A.R.; Jones, D.L.; Godbold, D.L.

\title{
Forest Ecology and Management
}

DOI:

10.1016/j.foreco.2015.07.018

Published: 26/07/2015

Peer reviewed version

Cyswllt i'r cyhoeddiad / Link to publication

Dyfyniad o'r fersiwn a gyhoeddwyd / Citation for published version (APA):

Ahmed, I. U., Smith, A. R., Jones, D. L., \& Godbold, D. L. (2015). Tree species identity influences the vertical distribution of labile and recalcitrant carbon in a temperate deciduous forest soil. Forest Ecology and Management, 359, 352-360.

https://doi.org/10.1016/j.foreco.2015.07.018

\footnotetext{
Hawliau Cyffredinol / General rights

Copyright and moral rights for the publications made accessible in the public portal are retained by the authors and/or other copyright owners and it is a condition of accessing publications that users recognise and abide by the legal requirements associated with these rights.

- Users may download and print one copy of any publication from the public portal for the purpose of private study or research

- You may not further distribute the material or use it for any profit-making activity or commercial gain

- You may freely distribute the URL identifying the publication in the public portal ?
}

Take down policy

If you believe that this document breaches copyright please contact us providing details, and we will remove access to the work immediately and investigate your claim. 
1 Tree species identity influences the vertical distribution of labile and recalcitrant

2 carbon in a temperate deciduous forest soil.

3

4 Iftekhar U. Ahmed ${ }^{1, *}$, Andrew R. Smith ${ }^{2}$, David L. Jones ${ }^{2}$, Douglas L. Godbold ${ }^{1}$

$5{ }^{1}$ Institute of Forest Ecology, Universität für Bodenkultur (BOKU), Vienna 1190,

$6 \quad$ Austria

$7 \quad{ }^{2}$ School of Environment, Natural Resources and Geography, Bangor University, Bangor, Gwynedd, LL57 2UW, UK

9

10 Author for correspondence:

Iftekhar U. Ahmed

Institute of Forest Ecology,

Universität für Bodenkultur (BOKU),

Vienna 1190,

Austria.

16

Corresponding author Tel.: +43 1476541001

17

Corresponding author Fax.: +43 1476544129

18

Corresponding author E-mail: iftekhar.ahmed@boku.ac.at

19

Number of Pages: 31

20

Number of Tables: $\quad 2$

21

Number of Figures: 5 


\section{Abstract}

In terrestrial environments, soil organic matter (SOM) is the largest organic carbon (C) pool. The quantity and quality of organic carbon in soils can be affected by vegetation through influencing the inputs and outputs of SOM. We examined how storage and quality of $\mathrm{C}$ in SOM were affected by vegetation under grass cover or single and a polyculture plot of Betula pendula, Alnus glutinosa and Fagus sylvatica. An acid hydrolysis approach was used to quantify three SOM fractions differing in biodegradability. Tree species identity and stand composition had no significant effect on the total amount of $\mathrm{C}$ stored in different SOM fractions to a depth of one meter. However, when examining individual SOM fractions in the upper layers of the soil profile, significantly more $\mathrm{C}$ was stored in the putatively more labile fractions 1 and 2 under F. sylvatica and A. glutinosa, respectively. In deeper soil layers, the highest storage of recalcitrant organic $\mathrm{C}$ was found under the tree polyculture. The vertical distribution of these three soil organic $\mathrm{C}$ pools was compared to $\mathrm{C}$ inputs via decomposed leaf litter. Our data indicated that in the tree species polyculture, combining litter inputs of multiple species can have a positive impact on the accumulation of acid resistant recalcitrant $\mathrm{C}$ in deep soil layers in 4 years. This $\mathrm{C}$ fraction has the greatest potential for long-term sequestration.

40

41 Keywords Fractionation; Acid hydrolysis; Polyculture; Carbon storage; Tree species 42 mixture; Decomposition 


\section{Introduction}

44 Soil organic matter (SOM) represents the largest reservoir of terrestrial organic carbon (C) on Earth, and the organic residues that comprise SOM range from relatively intact plant or microbial material to highly decomposed humic substances (Rumpel et al., 2002). Through differences in litter quality, plant species have potential to influence the storage and dynamics of $\mathrm{C}$ in soils, as reported in several previous studies (Binkley and Valentine, 1991; Hagen-Thorn et al., 2004; Jandl et al., 2007; Leuchner

et al., 2013). However, there is growing evidence that molecular structure is less

51 important than previously believed as a factor controlling the formation of SOM, and that the inputs from roots and microbial degradation products are more important than previously assumed (Schmidt et al., 2011). However, it remains undisputed that these factors result in a heterogeneous mixture of organic compounds (von Lützow et al., 2006; Schmidt et al., 2011; Tfaily et al., 2015).

To investigate the composition of soil organic matter, SOM can be fractionated into several pools using a range of techniques (eg. Paul et al., 2001; Weil et al., 2003; Gregorich et al., 2003; Bajgai et al., 2013). Each of these methods attempts to isolate soil organic matter pools of different longevity. A common method used, is to separate pools on the basis of biodegradability (Rovira and Vallejo,

61 2007). This method separates soil organic matter based on acid solubility into labile and recalcitrant pools, which are believed to have different turnover times

63 (McLauchlan et al., 2004). For example, labile C fraction composed of compounds such as soluble sugars, starch, and other carbohydrates, has been show to play a dominant role in the evolution of $\mathrm{CO}_{2}$ from soil due to preferential decomposition and rapid turnover (Belay-Tedla et al., 2009). In contrast the recalcitrant fraction is 
example, lignified humus and some physically protected labile SOM can be retained in soils for several thousand years (Zou et al., 2005; Dungait et al., 2012; Kellner et al., 2014). However, how the composition of aboveground vegetation affects the distribution of these pools in soil systems is largely unknown (De Deyn et al., 2008).

Tree species may influence soil organic carbon (SOC) stocks through a variety of mechanisms such as: (i) differences in net primary productivity and the production of detritus (Montagnini et al., 1993; Hansen et al., 2009), (ii) variation in the quality and complexity of organic matter input to soils detritus originating from leaf, root and mycorrhizal biomass (Hagen-Thorn et al., 2004), (iii) variation in the depth and distribution of roots (Carvalheiro and Nepstad, 1996; Lai et al., 2015), and (iv) by altering soil invertebrate and microbial populations (Hobbie et al., 2006; Lynch et al., 2012). Soil organic carbon accumulation may differ in species-diverse communities, compared to monocultures through variation in biomass inputs to soils, and SOM transformation processes in the soil (Steinbeiss et al., 2008). In mixed species communities, species interactions may either increase productivity through resource use complementarity (Loreau and Hector, 2001; Richards and Schmidt, 2010) or decrease productivity through inter- or intra-specific competition (Carnus et al., 2006). Plant community composition in mixtures may also influence long term storage of soil $\mathrm{C}$ through species-specific differences in plant detritus chemical composition and input rates (Six et al., 2002). In addition, interaction between litter types in mixed species communities may affect rates of decomposition and turnover (King et al., 2002). This is particularly true in natural forest ecosystems, where the litter layer can be comprised of inputs from many species, thus forming more complex organic substances compared to the litter layer of mono-specific forests. The highly complex and heterogeneous organic residues found in the SOM of mixed 
communities have been shown to alter soil $\mathrm{C}$ residence times through differences in biodegradability (Sollins et al., 1996).

Our study determined the vertical distribution of labile and recalcitrant $\mathrm{C}$ fractions in SOM that occurred within the initial four years of forest establishment. We examined the effects of vegetation on the storage of $\mathrm{C}$ fractions in soils under grass or trees of A. glutinosa, B. pendula, F. sylvatica grown in monoculture, or a polyculture of the three tree species. B. pendula is a light-demanding, early successional species with fast juvenile growth (Fischer et al., 2002). A. glutinosa is an $\mathrm{N}$-fixing, water-demanding pioneer species, also with high juvenile growth rates (Braun, 1974). Lastly, F. sylvatica is shade tolerant and slow growing when juvenile (Ellenberg et al., 1991), can persist in the understory, and often dominates late successional forest. We hypothesized that in the long term SOC storage would be positively affected by growing trees species selected for contrasting functional traits in polyculture.

\section{Materials and Methods}

\subsection{Study area}

The BangorDIVERSE experimental site was established at Henfaes Research Centre,Bangor University, North Wales, UK (53 $\left.14^{\prime} \mathrm{N}, 4^{\circ} 01^{\prime} \mathrm{W}\right)$ in March 2004 on two fields with a total area of 2.36 ha. Soils are fine loamy brown earth over gravel (Rheidol series) and classified as Fluventic Dystrochrept in the USDA system (Smith et al., 2013a). Soil texture in the $0-10 \mathrm{~cm}$ layer was $48.2 \pm 1.3 \%$ sand, $33.6 \pm 0.9 \%$ silt and $18.2 \pm 2.1 \%$ clay, determined by laser diffraction (Coulter LS particle size analyser). The soil $\mathrm{pH}$ is 5.4 in the $0-10 \mathrm{~cm}$ layer increases to 6.3 at $100 \mathrm{~cm}$ soil depth. Soil physicochemical properties are shown in Suppl. Table 1. Climate at the 
118 site is classified as hyperoceanic. Mean annual temperature throughout 2005-2008

119 was $11.5^{\circ} \mathrm{C}$ with an annual rainfall of $1034 \mathrm{~mm}$ (Campbell Scientific Ltd, Shepshed, 120 UK).

\subsection{Plantation design}

123 Before tree planting, all vegetation was removed from the fields including the grass 124 plots and the soil was ploughed and raked. Plots were established in four replicated 125 blocks of single species or two and three species mixtures of Alnus glutinosa L.,

126 Betula pendula Roth., Fagus sylvatica L., Fraxinus excelsior, Acer pseudoplatanus

127 L., Castanea sativa Mill. and Quercus robur L. The trees were selected due to their 128 contrasting shade tolerance, successional chronology and to represent a range of 129 taxonomic, physiological and ecological types. Two blocks were sited in each field 130 and the minimum distance between any two plots of the same composition was $35 \mathrm{~m}$.

131 The size of the plots were $62 \mathrm{~m}^{2}$ for the grassland, $81 \mathrm{~m}^{2}$ for single species, and 121 132 and $196 \mathrm{~m}^{2}$ for the two species and three species plots respectively. A replacement 133 series design (with inter-tree spacing constant between treatments) was selected 134 because of the experiments objective of being realistic in reflecting the practical 135 realities of how forests comprising monocultures or mixtures of potential canopy tree 136 species could be established (Jolliffe, 2000). The site was planted with $60 \mathrm{~cm}$ saplings

137 of each species with an inter-tree spacing of $1 \mathrm{~m}\left(10,000\right.$ stems $\left.^{-1}\right)$. A systematic 138 hexagonal planting design (Aguiar et al., 2001) was used to maximise the mixing 139 effect so that, in the three species mixture blocks, each tree was surrounded by nearest 140 neighbours of two-con-specific individuals and one and three individuals of the other 141 two species, respectively, resulting in each tree having six equidistant neighbours. On 142 the grassland plots, a grass cover was allowed to regenerate from remnants to form a 
143 sward composed of a mixture of Lolium perenne L., Dactylis glomerata L. and

144 Agrostis stolonifera L. In the work reported here, we used the plots of A. glutinosa, $B$.

145 pendula and $F$. sylvatica and a three species polyculture of these species.

\subsection{Positioning of the plots used}

148 The initial soil organic matter was determined in the top $0-10 \mathrm{~cm}$ layer on a $10 \times 10 \mathrm{~m}$ 149 grid. The mean SOM content across the fields was ca. $6 \%$, but across the fields varied 150 between 4 to $8 \%$ (Fig. 1). Historically, both fields were pasture, but since the 1980s

151 one field (field 1) was used for small scale forestry experiments, while in 2003 the 152 other field (field 2) was ploughed and planted with oil seed rape. Two blocks each 153 containing a replicate single species and mixed species plot as well as the associated 154 grassland plot, were located on the field used in 2003 for soil seed rape. In the other 155 field one block was positioned on an area previously planted with Salix as short 156 rotation coppice trial, while the other block was positioned on an area previously used 157 to grow mainly $Q$. robur and $F$. sylvatica saplings. In 2008 , one of the A. glutinosa 158 plots was damaged. To balance the number of replicates, one plot each of the $F$. 159 sylvatica, B. pendula and polyculture were removed from the analysis by random 160 selection, leaving the distribution of plots used as shown in Figure 1.

\subsection{Soil collection and sample processing}

163 Soil was collected by excavating $100 \times 100 \times 100 \mathrm{~cm}$ pits in the centre of each 164 grassland plot and each of the three tree species monoculture and tree three species 165 polyculture plots in September of 2008 (15 pits in total). In the polyculture plots,

166 samples were collected from a pit at an equal distance from A. glutinosa, B. pendula 167 and F. sylvatica. Soil samples were collected from seven layers (0-10, 10-20, 20-30, 
168

169

170

171

172

173

174

175

176

177

178

179

180

181

182

183

184

185

186

187

188

189

190

191

192

$30-40,40-50,70-80$ and $90-100 \mathrm{~cm})$. A subset of four layers $(0-10,10-20,40-50$ and

90-100 cm) were then used for $\mathrm{C}$ fractionation using acid hydrolysis. To ensure representativeness, samples were obtained from each layer, approximately $100 \mathrm{~g}$ of soil was collected from each side of the soil pit and mixed to produce a composite 400 g sample. Soils were then air dried, carefully homogenized and sieved to pass through a $2 \mathrm{~mm}$ sieve, a $50 \mathrm{~g}$ sub-sample was then taken and finely ground using a ball mill (Retsch Mixer Mill MM 200) and passed through a $100 \mu \mathrm{m}$ sieve prior to acid hydrolysis. Soil $\mathrm{pH}$ and electrical conductivity were determined in a 1:2 v/v slurry of soil and distilled water with standard electrodes. Moisture content was determined after drying at $105{ }^{\circ} \mathrm{C}$ for $72 \mathrm{~h}$, and organic matter as loss-on-ignition at $450{ }^{\circ} \mathrm{C}$ for $16 \mathrm{~h}$. Bulk density was determined using $100 \mathrm{~cm}^{3}$ cores and corrected for stone content (Rowell, 1994). The clay content of soils was determined by a simplified method combining wet sieving and sedimentation steps, as proposed by Kettler et al., (2001). Soil microbial biomass C of surface soil $(0-10 \mathrm{~cm})$ was determined according to the $\mathrm{CHCl}_{3}$ fumigation-extraction method of Vance et al., (1987).

\subsection{Leaf and root sample collection}

Fully expanded leaves exposed to full incident light, were collected from the outside of the crown at upper and middle of the canopy positions. Five trees of each species were randomly selected and approximately $2 \mathrm{~g}$ of leaves were collected and combined into a composite sample (ca. $10 \mathrm{~g}$ ) for each species. Root samples were collected using an $8 \mathrm{~cm}$ diameter soil corer. Grassland sward was collected from three undisturbed locations, washed and the leaves and roots separated before being oven dried at $80{ }^{\circ} \mathrm{C}$ for $24 \mathrm{~h}$. Dried leaves and roots were separately ground using a ball mill (Retsch Mixer Mill MM 200) and passed through a $100 \mu \mathrm{m}$ sieve. The total C 
193 content of soil and plant materials was determined using a TruSpec ${ }^{\circledR} \mathrm{CN}$ analyser

194 (Leco Corp., St Joseph, MI). The leaf and root materials were also analysed by

195 sequential acids hydrolysis as described below.

\subsection{Acid hydrolysis of soil and plant materials}

198 Chemical methods allow fractionation of SOC into pools of putative identity. For example in a two-step acid hydrolysis approach, the labile fraction is further divided into two pools- labile fraction 1 that could be putatively identified as polysaccharides,

201 derived from plant and microbial sources, and labile fraction 2 that contains cellulose 202 which is more resistant than fraction 1 (Rovira and Vallejo, 2007). Labile soil C 203 (fraction 1) was extracted from $0.5 \mathrm{~g}$ of air dried soil, which was taken from the 204 homogenised $50 \mathrm{~g}$ sample described above. The soil was transferred into a sealable 205 Pyrex tube and $15 \mathrm{ml}$ of $2.5 \mathrm{M} \mathrm{H}_{2} \mathrm{SO}_{4}$ was added and thoroughly mixed. The mixture 206 was heated to $100{ }^{\circ} \mathrm{C}$ for $30 \mathrm{~min}$ in a digestion block. After cooling the hydrolysed 207 solution was centrifuged at $2695 \times g$ for $3 \mathrm{~min}$ and the clear supernatant decanted into 208 a fresh glass tube. The residue was washed twice with $15 \mathrm{ml}$ of deionised water and 209 the washings added to the hydrolysate and kept in glass bottles at $4{ }^{\circ} \mathrm{C}$ until analysis 210 for $\mathrm{C}$ and $\mathrm{N}$ using a TOC-V-TN analyzer (Shimadzu Corp., Kyoto, Japan).

212 residues were transferred to Pyrex tubes and dried at $60{ }^{\circ} \mathrm{C}$. After cooling, $2 \mathrm{ml}$ of 13 $213 \mathrm{M} \mathrm{H}_{2} \mathrm{SO}_{4}$ was added, and the tubes were shaken overnight on a horizontal shaker at a 214 speed of 80 strokes $\min ^{-1}$ at room temperature. Thereafter, $26 \mathrm{ml}$ of deionised water 215 was added to dilute the acid to $1 \mathrm{M}$ and the residues were hydrolysed for $3 \mathrm{~h}$ at $100{ }^{\circ} \mathrm{C}$ 216 with occasional shaking. After centrifugation at $2695 \times g$ for 3 minutes, the clear 217 hydrolysate was removed. The residues were washed twice with distilled water, and 
the washings added to the hydrolysate and stored at $4{ }^{\circ} \mathrm{C}$ until analysis of $\mathrm{C}$ and $\mathrm{N}$ as

219 described above. The remaining residual $\mathrm{C}$ was fraction 3 and was calculated by

220 deducting the summed $\mathrm{C}$ fractions 1 and 2 from total organic $\mathrm{C}$ content of the soil

221 (Belay-Tedla et al., 2009).

Acid hydrolysis of plant material followed the same protocol used for soils except that the sample size was decreased to $25 \mathrm{mg}$ (Shirato and Yokozawa, 2006). The plant biomass $\mathrm{C}$ : acid ratio was the same as that used in the soil hydrolysis. As the residues could not be removed by centrifugation, the extracts were separated from un-hydrolysed residues by filtration using Whatman No. 1 filter papers (GE Healthcare UK Ltd.). After each hydrolysis, residues were washed twice with distilled 228 water. Both soil and plant samples were analysed in triplicate.

\subsection{Estimation of $C$ pools throughout the soil profile}

231 The total $\mathrm{C}$ stock and the absolute quantity of labile and recalcitrant $\mathrm{C}$ in different soil 232 layers were estimated on area basis using bulk density determination of the different 233 soil layers after adjustment for stone content. The total $\mathrm{C}$ pool size in soil profile (0$234100 \mathrm{~cm}$ ) was calculated by fitting a $2^{\text {nd }}$ order quadratic to the soil $\mathrm{C}$ data; predicted 235 values were then used to interpolate the $\mathrm{C}$ content of all soil layers in $10 \mathrm{~cm}$ 236 increments. The actual and in-filled values were then summed to determine total size 237 of the $\mathrm{C}$ pool.

\subsection{Leaf litter decomposition}

240 We studied the decomposition dynamics of leaf litter in each plots using leaf litter

241 from respective species to examine the impacts of species identity or mixture on 242 decay rates that affects the quality and quantity of SOC. We used leaves with a natural 
243 water content rather than air dried leaves, because firstly, most of the leaves reach the 244 forest floor as fresh litter in this ecosystem and thus we mimicked the natural process 245 and secondly, air drying can substantially depressed the initial decay rates, especially 246 in case of A. glutinosa (Taylor, 1998).

247 Litter decomposition rates were determined by mass loss of leaves in 180 248 nylon mesh bags. Fifteen litter bags $(1 \mathrm{~mm}$ mesh, $20 \mathrm{~cm} \times 15 \mathrm{~cm})$, containing $5.0 \mathrm{~g}$ 249 litter each, were placed on the forest floor of each tree species monoculture and the 250 three tree species polyculture plot in July 2009. The bags were deployed at close 251 contact with mineral soils under the litter layer to include the interaction of soil fauna 252 activities, especially as the activity of earthworms at the site is high (Scullion et al., 253 2014). Litter representing the three species polyculture plots was composed of $B$. 254 pendula, A. glutinosa and $F$. sylvatica in the ratios of 4:5:1 based on species 255 contributions to litter fall baskets within the polyculture plots (Ahmed, 2011). Three 256 litter bags were harvested after 3, 6, 10, 15 and 21 weeks from each plot. The litter 257 was cleaned to remove soil particles, and dried at $60{ }^{\circ} \mathrm{C}$ for $72 \mathrm{~h}$ before weighing. A 258 sub sample of $0.5-1.0 \mathrm{~g}$ was burned at $450{ }^{\circ} \mathrm{C}$ overnight, and weighed to determine 259 ash content. Ash weight was deducted from the total litter weight to account for the 260 contribution of adhered mineral soil particles to litter mass. The following single 261 exponential decay model (Equation 1; Olson, 1963) was used fitted to the leaf mass 262 loss data to compare leaf litter decay between species, where $A$ is the initial litter 263 mass, $k$ is the decay rate constant, and $t$ is time.

$$
\begin{array}{ll}
\text { mass remaining }=A e^{-k t} & \text { Equation } 1
\end{array}
$$

264 To determine the effect of litter mixture on litter decomposition, the mass loss 265 of the polyculture litter bags was compared with those of a theoretical polyculture 266 calculated from the mass loss of the single species litter bags. Equation 2 shows the 
267 theoretical mixture biomass calculation, where $M_{\text {species }}$ is the mass contributing 268 towards the mixture. The theoretical basis of this calculation is directly analogous to 269 the Relative Yield of Mixtures index used to quantify the effects of competition 270 (Wilson, 1988). The use of Equation 2 in this experiment is comparable with the

271 Relative Yield Total (Weigelt and Jolliffe, 2003).

272

$$
M_{\text {mixture }}=\left(\frac{4}{10} \times M_{\text {Betula }}\right)+\left(\frac{5}{10} \times M_{\text {Aln } u s}\right)+\left(\frac{1}{10} \times M_{\text {Fagus }}\right)
$$

Equation 2

2.9 Statistical analysis

276 The BangorDIVERSE experiment was designed as a fully replicated $(n=4)$ field experiment with seven tree species planted in monoculture and mixtures of two and 278 three species. For this research, three replicate plots each of grass, a single-tree 279 species or a three tree species polyculture were studied. C pools were compared 280 across four depths and four species types separately using One-way ANOVA, and 281 pairwise comparisons made with Tukey's HSD post hoc test (SPSS v14.0, SPSS Inc., 282 Chicago, IL, USA). Normality was assessed by Shapiro-Wilk test and homogeneity of 283 variances was determined by Levene's test. Main effects were considered to be 284 significant at $P<0.05$.

3. Results 
289 Total soil C content decreased with increasing depth in soils under all species types 290 and the grassland (Fig. 2). Significant differences in soil C between $F$. sylvatica plots

291 compared to $B$. pendula plots was observed at top two soil layers, but no differences

292 in soil $\mathrm{C}$ were found in any of the treatments in soil below $20 \mathrm{~cm}$. Soil microbial 293 biomass $\mathrm{C}$ ranged between $0.56 \pm 0.03 \mathrm{mg} \mathrm{C} \mathrm{kg}^{-1}$ and $0.83 \pm 0.08 \mathrm{mg} \mathrm{C} \mathrm{kg}^{-1}$ in the top 294 0-10 $\mathrm{cm}$ of soil, and the species composition had no significant impact on the 295 microbial biomass $\mathrm{C}$ and $\mathrm{N}$ content. In all the plots, the $\mathrm{C}: \mathrm{N}$ ratio decreased with 296 increasing soil depth (Suppl. Fig.1), but no statistically significant differences 297 between any of the treatments at any soil depth were observed However, the greatest 298 change in $\mathrm{C}: \mathrm{N}$ ratio between the top and bottom soil layers was found in the grassland 299 and the B. pendula plots ( $\Delta 6.1)$ compared to a change of ca. 3.5 in the A. glutinosa, $300 \quad$ F. sylvatica and polyculture plots.

\subsection{Relative contribution of $C$ fractions to total $C$ concentration}

303 The C content of each of the SOM fractions varied between species and between soil

304 depths. Figure 3 illustrates the distribution pattern of three $\mathrm{C}$ fractions in soils under 305 different plant species and polyculture. In the 0-10 cm layer, fraction 1 was between $30622-36 \%$ of the total $\mathrm{C}$, this increased to $29-52 \%$ at $100 \mathrm{~cm}$ depth. The $\mathrm{C}$ of 307 fraction 1 in the $F$. sylvatica plots was significantly $(P=0.012 \& P=0.002)$ greater 308 than the soils of A. glutinosa plots at top two layers, and at 10-20 cm depth $B$. 309 pendula and the polyculture soils were significantly higher than A. glutinosa ( $B$. 310 pendula, $P=0.006$; polyculture, $P=0.035$ ). For fraction 2 , except in the grassland plots, 311 the changes in percentage contribution to the total soil $\mathrm{C}$ were less pronounced 312 compared to fraction 1 . Grassland contained a significantly higher percentage of $\mathrm{C}$ in 313 fraction 2 in all soil layers than other plots, except A. glutinosa. 
Fraction 3, the residual $\mathrm{C}$ after extraction, representing potentially the most recalcitrant $\mathrm{C}$ was unaffected by soil depth in $F$. sylvatica and the polyculture, but was significantly lower in the middle layer $(40-50 \mathrm{~cm})$ compared to the upper layers in the B. pendula and A. glutinosa plots. Species identity and mixture did not significantly

318 affect the relative contribution of fraction 3 in the top two layers of soil (Fig. 3).

319 Further down the soil profile, a significantly higher percentage of fraction 3 was 320 found in polyculture soils than in B. pendula $(P=0.014)$ and A. glutinosa $(P=0.002)$ 321 soils at $40-50 \mathrm{~cm}$; and in the $100 \mathrm{~cm}$ layer the contribution was higher compared to $A$. 322 glutinosa $(P=0.013)$. In both the $40-50$ and $100 \mathrm{~cm}$ layers, $A$. glutinosa had the lowest 323 proportion of $\mathrm{C}$ within fraction 3 (27 and $34 \%$, respectively).

\subsection{Total C storage and $C$ pool size of each fraction}

326 The total $\mathrm{C}$ storage to a depth of $100 \mathrm{~cm}$ in the various plots ranged between $10.2 \pm$ 3270.9 under grass to $6.9 \pm 0.8 \mathrm{~kg} \mathrm{C} \mathrm{m}^{-2}$ under $F$. sylvatica, with no significant variation 328 between the treatments (Table 1). In Table 1 the pools of $\mathrm{C}$ are shown as the total 329 extractable (fraction 1 and fraction 2) and the residual $\mathrm{C}$ in fraction 3 . The tree species 330 grown in monoculture and polyculture showed no significant difference in total $\mathrm{C}$ 331 stocks. We examined the influence of tree species on fraction 3 in upper $(0-40 \mathrm{~cm})$ 332 and lower $(40-100 \mathrm{~cm})$ region of the soil profile (Fig. 4). In the upper layers no 333 significant differences were found between the treatments, however in the deeper soil 334 layers, the greatest storage of $\mathrm{C}$ in fraction 3 was found in the polyculture. The $\mathrm{C}$ 335 storage in the polyculture soil at depth was significantly greater compared to the $B$. 336 pendula, A. glutinosa and grassland soil, but not statistically different compared to $F$. 337 sylvatica. Both F. sylvatica and the polyculture in the lower soil profile had a 
338 significantly higher $(P=0.015$ and $P<0.001) \mathrm{C}$ storage in fraction 3 compared to the 339 profile under grass.

\subsection{Fractionation of litter $C$ inputs}

342 Total $\mathrm{C}$ in the leaves and roots of the three tree species was 52 and $53 \%$, 343 respectively, significantly greater than the sward comprising the grassland which 344 contained $44 \%(P=0.020)$ and $40 \%(P=0.002)$ for leaves and roots, respectively. In 345 the tree leaves, $\mathrm{C}$ extracted from fractions 1 and 2, was similar. In contrast, in the 346 roots of $F$. sylvatica the $\mathrm{C}$ content of fraction 2 was higher than in the other tree 347 species (Fig. 5). In grass leaves and roots, the highest amount of $\mathrm{C}$ was in fraction 1, 348 and the amount of fraction 3 was only 35 and $37 \%$ of the total $\mathrm{C}$, for leaves and roots, 349 respectively.

\subsection{Leaf litter decomposition}

352 During the course of decomposition, mass remaining in leaf litter best fitted a first 353 order exponential decay model. Decay rate coefficients for the three species grown in 354 monoculture and polyculture are shown in (Table 2). Overall, and during the first four 355 sampling intervals $(3,6,10 \& 15$ weeks $)$, there was a significant difference in mass 356 loss between the litter of tree species $(P<0.001$; Table 2$)$. During this period the rate 357 of mass loss of the single species trees litter was highest in A. glutinosa, which was 3581.94 and 1.80 times faster than $F$. sylvatica and B. pendula, respectively (Table 2). In 359 the mixed species litter bags there was a dramatic and significant $(P<0.001)$ reduction 360 in mass loss, which was 4.36 times slower than A. glutinosa in monoculture.

\section{Discussion}


365 The storage and the distribution of organic $\mathrm{C}$ in soils are influenced by the quality and 366 quantity of inputs determined by the integrated effects of species-specific traits 367 (Schmidt et al., 2011). In this study, we examined three tree species selected due to 368 their strongly contrasting productivity and functional traits, to accentuate the species369 specific contribution to soil $\mathrm{C}$ pools. As a consequence of the trait differences, the 370 species have different qualities of leaf litter inputs (see below), but also different rates 371 of fine root turnover and hence root litter inputs (Smith et al., 2013b). The differences 372 in leaf litter quality were reflected in the initial rates of decomposition, where the 373 decomposition of $A$. glutinosa was nearly two times faster than the other two species. 374 We found that decomposition processes of mixed species litter bags were slower than 375 single species when deployed at our field site. Species-specific interactions during 376 litter decomposition have been shown to have no effect (Prescott et al., 2000), retard 377 (Chapman et al., 1988), or enhance decomposition processes (de Marco et al., 2011). 378 We attribute the reduction in decomposition rates to the combination of a highly 379 recalcitrant lignocellulose matrix of $F$. sylvatica litter and species-specific secondary 380 metabolites, such as polyphenols and monoterpenes that inhibit $\mathrm{N}$ mineralisation and 381 species-specific decomposer communities (Hattenschwiler et al., 2005). In addition to 382 the potential interaction of late successional species litter chemistry in decomposition, 383 and consistent with the findings of Giertych et al. (2006), we found a higher water384 soluble polyphenolic content in B. pendula $\left(20.5 \mathrm{mg} \mathrm{L}^{-1}\right)$ compared to A. glutinosa 385 (17.5 $\mathrm{mg} \mathrm{L}^{-1}$ ) litter (Ahmed, 2011). The nitrogen content of senesced leaf litter was $38630.5,29.0$ and $35.0 \mathrm{~g} \mathrm{~kg}^{-1}$ for F. sylvatica, B. pendula and A. glutinosa, respectively, 387 suggesting that the rapid initial decomposition of A. glutinosa was driven by nitrogen 
availability. However, lignin content did not follow the same species order and was 138, 272 and $338 \mathrm{~g} \mathrm{~kg}^{-1}$ for A. glutinosa, B. pendula and F. sylvatica, respectively, potentially leading to slower decomposition of fraction $3 \mathrm{C}$ for $F$. sylvatica relative to the other species.

Plant species identity can also influence the production and distribution of fine root biomass throughout the soil profile. The effect of species diversity on root biomass and production is extremely variable with studies showing no effect (Bauhus et al., 2000), a reduction (Bolte and Villanueva, 2006) or increase (Brassard et al., 2011). In the species used here, A. glutinosa had the highest rate of fine root turnover, and F. sylvatica the highest fine root length in the top $30 \mathrm{~cm}$ of soil (Smith et al., 2013b). However, differences in the rate of fine root turnover were not seen in all years (Ahmed, 2011). In addition to the influence of plant litter chemistry and species identity on decomposition, the phenology of leaf and root growth can also influence belowground processes (Niinemets and Tamm, 2005). Indeed, seasonality has a particularly strong control on the phenology of grassland species (Steinaker and Willson, 2008).

\subsection{Organic C storage of soils under different plant species}

No significance difference in SOC stock $(0-100 \mathrm{~cm})$ was observed both between the tree species, and in comparison to the grassland (Table 1). This is in consistent with the study of Vesterdal et al. (2008), who reported no significant variation in the soil C stocks of five European broadleaved tree species, including $F$. sylvatica, after 30 years of growth. However, we did find a higher organic C concentration in B. pendula soil compared to F. sylvatica in the upper two layers of the soil profile (Fig. 2). The biomass production and subsequent litter fall in B. pendula was much higher than the 
413 late successional species $F$. sylvatica, and may be the cause of the higher SOC in the 414 upper soil layers.

\subsection{Soil organic carbon and fractionation}

417 Changes in total soil $\mathrm{C}$ were only observed in the top $20 \mathrm{~cm}$ of soil, below this depth 418 soil $\mathrm{C}$ was not different between the tree species or the grassland. Soil C stock change 419 and physical fractionation were investigated at the Bangor site using different but 420 adjacent plots with the same species by Hoosbeek et al., (2011), who found an

421 increase of $530 \mathrm{~g} \mathrm{C} \mathrm{m}^{-2}$ in the top $0-10 \mathrm{~cm}$ layer 4 years after planting. In contrast to 422 our chemical fractionation results, the distribution of course, fine and aggregate 423 particulates were similar between all species and the polyculture. Here we showed 424 that using chemical fractionation, the organic $\mathrm{C}$ content of fraction 1 was significantly 425 lower in soils under A. glutinosa than in F. sylvatica in the $0-10 \mathrm{~cm}$ soil layer (Fig. 3). 426 We propose two mechanisms to explain our observed differences in fraction $1 \mathrm{C}$ 427 content. First, relative to $F$. sylvatica, A. glutinosa is poor at translocating nutrients 428 and carbohydrates during senescence (Lecerf and Chauvet, 2008), and subsequently 429 the senesced litter of A. glutinosa is considered to be of high quality due to thick, 430 mesophyll rich, leaves with a low $\mathrm{C}: \mathrm{N}$ ratio. These traits, which are favourable to 431 grazing by soil organisms and microbial decomposition (Kazakou et al., 2009), 432 probably resulted in a rapid removal of fraction 1 . The influence of litter quality on 433 decomposition processes was also supported by significantly faster litter mass loss of 434 A. glutinosa than F. sylvatica during the first three weeks (Table 2). Second, during 435 organic matter mineralization and microbial turnover, $\mathrm{C}$ not respired as $\mathrm{CO}_{2}$ is 436 retained within microbial biomass, or released as dissolved organic carbon (DOC), 
which then leaches through the soil profile reducing the size of the pool in shallow soil layers (Currie and Aber, 1997).

The percentage of $\mathrm{C}$ in fraction 1 increased gradually down the soil profile under B. pendula and A. glutinosa, but remained constant under F. sylvatica and the

441 polyculture. Studies using stable $\mathrm{C}$ isotopes and radiocarbon have revealed that acid 442 hydrolysable $\mathrm{C}$, as in fraction 1 , as well as mineral associated $\mathrm{C}$ are consistently 443 younger than other fractions (Leavitt et al., 1997), and generally, it is assumed that the 444 age of soil C increases with depth (Fontaine et al., 2007). Potential sources of the 445 fraction 1 in the lower soil layers are numerous and include translocation from upper 446 soil layers with DOC or bioturbation, root exudates (de Graaff et al., 2010), and 447 priming of more recalcitrant soil organic matter (Rovira and Vallejo, 2007, Kogel448 Knabner et al. 1991) with subsequent release of more labile fractions. Earthworm 449 activity at the site is high, and the earthworms were shown to have a higher preference 450 for litter from B. pendula and A. glutinosa than that from F. sylvatica (Scullion et al. $4512014)$.

452 The largest percentage of $\mathrm{C}$ in the top soil layer was in fraction 3, and was not 453 influenced by tree species identity or grass. This is consistent with the findings of 454 Hoosbeek et al., (2011) who reported that the physical fractionation of particulate 455 organic matter at the same experiment site and found that tree species identity had no 456 effect on soil $\mathrm{C}$ stabilization processes and microaggregate protection in the upper soil 457 layers. A caveat of our acid hydrolysis approach to separating $\mathrm{C}$ fractions is that 458 physically protected labile C may be included in fraction 1 (McLauchlan and Hobbie, 459 2004), but there seems to be broad agreement between the acid hydrolysis and 460 physical fractionation methods. Similarly, it has also recently be shown that using 461 acid fractionation schemes more aggressive than the one used here, can lead to de- 
novo synthesis of non-hydrolysable substances and loss of pure model carbohydrates

463 (Greenfield et al. 2013).

Soils from under grass differed strongly to the tree plots in the distribution of

465 all three $\mathrm{C}$ fractions. Throughout the soil profile, the strong difference between trees

466 and grass were most likely attributable to a shallow rooting depth and turnover of 467 non-woody grass roots. In addition, the higher amount of fraction $1 \mathrm{C}$ in grassland soil 468 might be due to the high quality of grass litter, which contains substantially less lignin 469 than tree litter, and thus is easily decomposed (Deschaseaux and Ponge, 2001). This is 470 supported by our analysis of grass leaf and root material, which showed much higher 471 quantities of fraction $1 \mathrm{C}$ in grass than in tree materials (Fig. 5).

\subsection{Recalcitrant $C$ in deep soil layers}

474 There were no differences in the percentage of soil $\mathrm{C}$ found at $40-100 \mathrm{~cm}$ soil depth 475 between the treatments. Below $40 \mathrm{~cm}$ the percentage soil $\mathrm{C}$ was less than $1 \%$. 476 However, surprisingly, significantly greater quantities of the total soil $\mathrm{C}$ were found in 477 fraction 3 in the three species tree polyculture stands, compared to the single species 478 stands of $B$. pendula and A. glutinosa and the grassland. The higher fraction 3 storage 479 was found in all three replicate polyculture plots irrespective of previous land-use 480 (Fig. 1), as was the lower fraction 3 storage in the grassland plots. Similarly, in the 481 polyculture plots, there were no obvious differences in soil texture, such as high levels 482 of clay, which could account for the increased fraction 3 storage. The higher fraction 4833 storage in polyculture is difficult to reconcile with either $\mathrm{C}$ inputs via above- or 484 below-ground biomass of the different species. By far the biggest difference in 485 fraction 3 storage, or the percentage of fraction 3 in the total soil $\mathrm{C}$, was found when 486 the trees were compared to the grassland. This suggests that the differences in fraction 
3 storage could be related to depth distribution and timing of $\mathrm{C}$ inputs, litter quality, or quantity. A potential mechanism could be a priming effect, where the input of labile

C products into the deep soil layers, possibly via the flow of DOC stimulated

490 microbial mineralisation of old C (Kuzyakov et al., 2000; Hoosbeek et al., 2004).

491 Microbial priming of deep soil C was reported by Fontaine et al., (2004) who

492 demonstrated that fresh inputs of labile $\mathrm{C}$ allowed the co-metabolism of old 493 recalcitrant $\mathrm{C}$ by the microbial community at a depth of $60-80 \mathrm{~cm}$. Therefore, the 494 availability of easily biodegradable compounds through vertical DOC transport into 495 deep soil layers could be an important factor in mediating the storage of recalcitrant C 496 in deep soil layers. The chemical composition of DOC is related to the plant litter 497 from which it is derived (Hansson et al., 2010). Our leaf litter decomposition 498 experiment showed a large and significant difference between the rate of 499 decomposition in monoculture and the three species polyculture, which may have 500 resulted in a greater amount of recently derived $\mathrm{C}$ moving down the soil profile and 501 microbial priming fraction 3 at depth. Again difficult to reconcile with current ideas 502 is the speed at which these changes must have occurred. However, it must be stressed 503 that the levels of total $\mathrm{C}$ at $100 \mathrm{~cm}$ soil depth are very low, enabling detection of small 504 changes.

505 To conclude, our data suggest that even within relatively short time scales 506 vegetation types and tree species identity and mixtures can influence both 507 accumulation of soil $\mathrm{C}$ in surface layers, but also the storage of more recalcitrant 508 fractions in deeper soil layers. This may be due to the direct inputs of new C, but also 509 due to the effects of new $\mathrm{C}$ influencing the levels and distribution of old soil C.

\section{Acknowledgements}


512 The experimental facility was supported by the INTERREG IVB North-West Europe 513 project 003A ForeStClim. IUA was supported both by ForeStClim and by the 514 Forestry Commission UK for part of the work. The authors would like to thank Llinos 515 Hughes and Mark Hughes of Henfaes Reasearch Farm, Bangor University for their 516 help in sampling and processing of soils. We would like to thanks the two anonymous 517 reviewers for their very constructive suggestions which were definitely helpful to 518 improve the quality of the article.

\section{References}

521 Aguiar, F.C., Ferreira, M.T., Moreira, I. 2001. Exotic and native vegetation establishment following channelization of a western Iberian river. Regul. River, 17, 509-526.

Ahmed, I.U. 2006. Leaf decomposition of birch (Betula pendula), alder (Alnus glutinosa) and beech (Fagus sylvatica) grown under elevated atmospheric $\mathrm{CO}_{2}$. Master thesis, SENRGY, Bangor University, Bangor, UK.

Ahmed, I.U. 2011. Ecosystem carbon dynamics: as influenced by tree species and mixture in temperate deciduous woodland. PhD dissertation, SENRGY, Bangor University, Bangor, UK.

Bajgai, Y., Hulugalle, N., Kristiansen, P., McHenry, M. 2013. Developments in Fractionation and Measurement of Soil Organic Carbon: A Review. Open J. Soil Sci., 3(8), 356-360.

533 Bauhus. J., Khanna, P.K., Menden, N. 2000. Aboveground and belowground interactions in mixed plantations of Eucalyptus globulus and Acacia mearnsii. Can. J. For. Res., 30, 1886-1894. 
Belay-Tedla, A., Zhou, X., Su, B., Wan, S., Luo, Y. 2009. Labile, recalcitrant and microbial carbon and nitrogen pools of a tall grass prairie soil in the US Great Plains subjected to experimental warming and clipping. Soil Biol. Biochem., $41,110-116$.

Binkley, D., Valentine, D. 1991. Fifty-year biogeochemical effects of green ash, white pine, and Norway spruce in a replicated experiment. For. Ecol. Manage., 40, $13-25$.

Bolte, A., Villanueva, I. 2006. Interspecific competition impacts on themorphology and distribution of fine roots in European beech (Fagus sylvatica L.) and Norway spruce (Picea abies (L.) Karst.). Eur. J. For. Res., 125, 15-26.

Brassard, B.W., Chen, H.Y.H., Bergeron, Y., Paré, D. 2011. Differences in fine root productivity between mixed- and single-species stands. Func. Ecol., 25, 238246.

Braun, H.J. 1974. Rhytmus und Grösse von Wachstum, Wasserverbrauch und Produktivität des Wasserverbrauches bei Holzpflanzen. Allg Forst-und JagdZtg 145, 81-86.

Carnus, J., Parrotta, J.A., Brockerhoff, E., Arbez, M., Jactel, H., Kremer, A., Lamb, D., O’Hara, K., Walters, B. 2006. Planted forests and biodiversity. J. For., 104, $65-77$.

Carvalheiro, K.D., Nepstad, D.C. 1996. Deep soil heterogeneity and fine root distribution in forests and pastures of eastern Amazonia. Plant Soil, 182, 279285.

Chapman, K., Whittaker, J.B., Heal, O.W. 1988. Metabolic and faunal activity in litters of tree mixtures compared with pure stands. Agric. Ecosys. Environ., $24,33-40$. 
561 Currie, W.S., Aber, J.D. 1997. Modelling leaching as a decomposition process in humid Montana forests. Ecol., 78, 1844-1860.

563 De Deyn, G.B., Cornelissen, J. H. C., Bardgett, R.D. 2008. Plan functional traits and soil carbon sequestration in contrasting biomes. Ecol. Lett., 11, 1-16.

de Graaff, M.A., Classen, A.T., Castro, H.F., Schadt, C.W. 2010. Labile soil carbon inputs mediate the soil microbial community composition and plant residue decomposition rates. New Phytol., 188, 1055-1064.

de Marco, A., Meola, A., Maisto, G., Giordano, M., de Santo, A.V. 2011. Nonadditive of leaf litters in a Mediterranean maquis effects of litter mixtures on decomposition. Plant Soil, 344, 305-331.

571 Deschaseaux, A., Ponge, J.F. 2001. Changes in the decomposition of humus profiles near the trunk base of an oak tree (Quercus petraea (Mattus) Liebl). European J. Soil Biol., 37, 9-16.

Dungait, J.A.J., Hopkins, D.W., Gregory, A.S., and Whitmore, A.P. 2012. Soil organic matter turnover is governed by accessibility not recalcitrance. Glob. Chang. Biol., 18, 1781-1796.

Ellenberg, H., Weber, H.E., Düll, R., Wirth, V., Werner, W., Paulissen, D. 1991. Zeigerwerte von Pflanzen in mitteleuropa. Scr. Geobot., 18, 248.

579 Fischer, H., Bens, O., Huttl, R.F. 2002. Changes in humus form, humus stock and soil organic matter distribution caused by forest transformation in the NorthEastern lowlands of Germany. Forstwiss Cent., 121, 322-334. organic carbon in deep soil layers controlled by fresh carbon supply. Nat., 450, 277-281. 
585 Fontaine, S., Bardoux, G., Abbadie, L., Mariotti, A. 2004. Carbon input to soil may decrease soil carbon content. Ecol. Lett., 7, 314-320.

587 Giertych, M.J., Karolewski, P., Zytkowiak, R., Oleksyn, J. 2006. Differences in defence strategies against herbivores between two pioneer tree species, Alnus glutinosa L. Gaertn. and Betula pendula Roth. Polish J. Ecol., 54, 181-187.

Greenfield, L. G., Gregorich, E. G., van Kessel, C., Baldock, J. A., Beare, M. H., Billings, S. A., Clinton, P. W., Condron, L. M., Hill, S., Hopkins, D. W., Janzen, H. H. 2013. Acid hydrolysis to define a biologically-resistant pool is compromised by carbon loss and transformation. Soil Biol. Biochem., 64, 122-126.

Hagen-Thorn, A., Callesen, I., Armolaitis, K., Nihlgard, B. 2004. The impact of six European tree species on the chemistry of mineral topsoil in forest plantations on former agricultural land. For. Ecol. Manage., 195, 373-384.

Hansen, K., Vesterdal, L., Schmidt, I.K., Gundersen, P., Sevel, L., Bastrup-Birk, A., Pedersen, L.B., Bille-Hansen, J. 2009. Litterfall and nutrient return in five tree

Hansson, K., Kleja, D.B., Kalbitz, K., Larsson, H. 2010. Amounts of carbon mineralised and leached as DOC during decomposition of Norway spruce needles and fine roots. Soil Biol. Biochem., 42, 178-185.

Hattenschwiler, S. 2005. Effects of tree species diversity on litter quality and decomposition. In: Scherer-Lorenzen M, Korner CH, Schulze ED (eds) Forest diversity and functions, temparate and boreal systems. Ecological Studies 176. Springer-Verlag, Berlin, pp 149. 
608

609

610

611

612

613

614

615

616

617

618

619

620

Hobbie, S.E., Reich, P.B., Oleksyn, J., Ogdahl, M., Zytkowiak, R., Hale, C., Karolewski, P. 2006. Tree species effects on decomposition and forest floor dynamics in a common garden. Ecol., 87, 2288-2297.

Hoosbeek, M.R., Lukac, M., Velthorst, E.J., Smith, A.R., Godbold, D.L. 2011. Free atmospheric $\mathrm{CO}_{2}$ enrichment did not affect symbiotic $\mathrm{N}_{2}$-fixation and soil carbon dynamics in a mixed deciduous stand in Wales. Biogeosciences, 8, $353-364$.

Hoosbeek, M.R., Lukac, M., van Dam, D., Godbold, D.L., Velthorst, E.J., Biondi, F.A., Peressotti, A., Cotrufo, M.F., de Angelis, P., Scarascia-Mugnozza, G .2004. More new carbon in the mineral soil of a Poplar plantation under Free Air Carbon Enrichment (POPFACE), Cause of increased priming effect? Glob Biogeochem. Cycles, 18, GB1040.

Jandl, R., Lindner, M., Vesterdal, L., Bauwens, B., Baritz, R., Hagedorn, F., Johnson, D.W., Minkkinen, K., Byrne, K.A. 2007. How strongly can forest management influence soil carbon sequestration? Geoderma, 137, 253-268.

Jolliffe, P.A. 2000. The replacement series. J. Ecol. 88, 371-385.

Kazakou, E., Violle, C., Roumet, C., Pintor, C., Gimenez, O., Garnier, E. 2009. Litter quality and decomposability of species from a Mediterranean succession depend on leaf traits but not on nitrogen supply. Annu. Bot., 104, 1151-1161.

Kellner H, Luis P, Pecyna MJ, Barbi F, Kapturska, D. 2014. Widespread Occurrence of Expressed Fungal Secretory Peroxidases in Forest Soils. PLoS ONE., 9(4): e95557.

Kettler, T.A., Doran, J.W., Gilbert, T.L. 2001. Simplified Method for Soil ParticleSize Determination to Accompany Soil-Quality Analyses. Soil Sci. Soc. Am. J., 65, 849-852. 
633 King, R.F., Dromph, K.M., Bardgett, R.D. 2002. Changes in species evenness of litter have no effect on decomposition processes. Soil Biol. Biochem., 34, 19591963.

636 Kogel-Knabner, I., Hatcher, P.G., Zech, W. 1991. Chemical structural studies of forest soil humic acids: aromatic carbon fraction. Soil Sci. Soc.Am. J., 55,

Kuzyakov, Y., Friedel, J.K., Stahr, K. 2000. Review of mechanisms and quantification of priming effects. Soil Biol. Biochem., 32, 1485-1498.

Lai, Z., Zhang, Y., Liu, J., Wu, B., Qin, S., Fa, K., 2015. Fine-root distribution, production, decomposition, and effect on soil organic carbon of three revegetation shrub species in northwest China. Forest Ecol. Manag., ( $\underline{\text { doi:10.1016/i.foreco.2015.04.025) }}$

Leavitt, S.W., Follett, R.F., Paul, E.A. 1997. Estimation of slow and fast cycling soil organic carbon pools from 6N HCl hydrolysis. Radiocarb., 38, 231-239.

Lecerf, A., Chauvet, E. 2008. Intraspecific variability in leaf traits strongly affects alder leaf decomposition in a stream. Basic App. Ecol., 9, 598-605.

Leuschner, C., Wulf, M., Bäuchler, P., Hertel, D. 2013. Soil C and nutrient stores under Scots pine afforestations compared to ancient beech forests in the German Pleistocene: The role of tree species and forest history. For. Ecol. Manage., 310, 405-415.

Loreau, M., Hector, A. 2001. Partitioning selection and complementarity inbiodiversity experiments. Nat., 412, 72-76. Species Effect on the Soil Microbial Community in a Montane Tropical Forest. Pacific Science., 66(2), 141-150. 
658

659

660

661

662

663

664

665

666

667

668

669

670

671

672

673

674

675

676

677

678

679

680

McLauchlan, K., Hobbie, S.E. 2004. Comparison of labile soil organic matter fractionation techniques. Soil Sci. Soc. Am. J., 68, 1616-625.

Montagnini, F., Ramstad, K., Sancho, F. 1993. Litterfall, litter decomposition and the use of mulch of four indigenous tree species in the Atlantic lowlands of Costa Rica. Agrofor. Sys., 23, 39-61.

Niinemets, U., Tamm, U. 2005. Species differences in timing of leaf fall and foliage chemistry modify nutrient resorption efficiency in deciduous temperate forest stands.Tr. Physiol., 25(8), 1001-1014.

Olson, J.S. 1963. Energy storage and the balance of producers and decomposers in ecological systems. Ecol., 44, 322-331.

Paul, E. A., Morris, S. J., Bohm, S. 2001. Determination of soil carbon pool sizes and turn-over rates: Biophysical fractionation and tracers. In Assessment Methods for soil carbon. Lal, R. (ed.). Lewis Publ., Boca Raton, FL. 193-206.

Prescott, C.E., Zabek, L.M., Staley, C.L., Kabzerns, R. 2000. Decomposition of broadleaf and needle litter in forests of British Columbia: influence of litter types, forest types and litter mixtures. Can. J. For. Res., 30, 1742-1750.

Richards, A.E., Schmidt, S. 2010. Complementary resource use by tree species in a rain forest tree plantation. Ecol. Appl., 20(5), 1237-54.

Rovira, P., Vallejo, V.R. 2002. Labile and recalcitrant pools of carbon and nitrogen in organic matter decomposing at different depths in soils an acid hydrolysis approach. Geoderma., 107, 109-141.

Rovira, P., Vallejo, V.R. 2007. Labile and recalcitrant and inert organic matter in Mediterranean forest soils. Soil Biol. Biochem., 39, 202-215.

681 Rowell, D.L. 1994. Soil science methods and applications. Pearson, London 
Rumpel, C., Kogel-Knabner, I., Bruhn, F. 2002. Vertical distribution, age and chemical composition of organic carbon in two forest soils of different pedogenesis. Org. Geochem., 33, 1131-1142.

Schmidt, M.W.I., Torn, M.S., Abiven, S., Dittmar, T., Guggenberger, G., Janssens, I.A., Kleber, M., Kögel-Knabner, I., Lehmann, J., Manning, D.A.C., Nannipieri, P., Rasse, D.P., Weiner, S., Trumbore, S.E. 2011. Persistence of soil organic matter as an ecosystem property. Nat., 478, 49-56.

Scullion, J., Smith, A.R., Gwynn-Jones, D., Jones, D.L., Godbold, D.L. 2014. Deciduous woodland exposed to elevated atmospheric $\mathrm{CO}_{2}$ has speciesspecific impacts on anecic earthworms. App. Soil Ecol., 80, 84-92.

Six, J., Conant, R.T., Paul, E.A., Paustian, K. 2002. Stabilization mechanisms of soil organic matter, implications for C-saturation of soils. Plant Soil, 241, 155176.

Smith, A.R., Lukac, M., Bambrick, M., Miglietta, F., Godbold, D.L. 2013a. Tree species diversity interacts with elevated $\mathrm{CO}_{2}$ to induce a greater root system response. Glob. Chang. Biol., 19, 217-228.

Smith, A.R., Lukac, M., Hood, R., Miglietta, F., Godbold, D.L. 2013b. Elevated $\mathrm{CO}_{2}$ enrichment induces a differential biomass response in a mixed species temperate forest plantation. New Phyt., 198, 156-168.

Sollins, P., Homann, P., Caldwell, B.A. 1996. Stabilization and destabilization of soil organic matter, mechanisms and controls. Geoderma, 74, 65-105.

Shirato, Y., Yokozawa, M. 2006. Acid hydrolysis to partition plant material into decomposable and resistant fractions for use in the Rothamsted carbon model. Soil Biol. Biochem., 38, 812-816. 
Steinaker, D.F., Wilson, S.D. 2008. Phenology of fine roots and leaves in forest and grassland. J. Ecol., 96(6), 1222-1229.

Steinbeiss, S., Temperton, V.M., Gleixner, G. 2008. Mechanisms of short-term soil carbon storage in experimental grasslands. Soil Biol. Biochem., 40, 26342642.

Taylor, B.R. 1998. Air drying depresses rates of leaf litter decomposition. Soil Biol. Biochem., 30, 403-412.

Tfaily, M.M., Chu, R.K., Tolic, N., Roscioli, K.M., Anderton, C.R., Pasa-Tolic, L., Robinson, E.W., Hess, N.J., 2015. Advanced Solvent Based Methods for Molecular Characterization of Soil Organic Matter by High-Resolution Mass Spectrometry. Anal. Chem., 87, 5206-5215.

Vance, E.D., Brookes, P.C., Jenkinson, D.S. 1987. An extraction method for measuring microbial biomass C. Soil Biol. Biochem., 19, 703-707.

Vesterdal, L., Schmidt, I. K., Callesen, I., Nilsson, L. O., Gundersen, P. 2008. carbon and nitrogen in forest floor and mineral soil under six common European tree species For. Ecol. Manage., 255, 35-48.

von Lützow, M., Kögel-Knabner, I., Ekschmitt, K., Matzner, E., Guggenberger, G., Marschner, B., Flessa, H. 2006. Stabilization of organic matter in temperate soils, mechanisms and their relevance under different soil conditions - a review. Euro. J. Soil. Sci., 57, 426-445.

Weigelt, A., Jolliffe, P. 2003. Indices of plant competition. J. Ecol., 91, 707-720.

Wilson, J.B. 1988. Shoot competition and root competition. J. Appl. Ecol., 25, 279296.

Zou, X.M., Ruan, H.H., Fu, Y., Yang, X.D., Sha, L.Q. 2005. Estimating soil labile organic carbon and potential turnover rates using a sequential fumigationincubation procedures. Soil Biol. Biochem., 37, 1923-1928. 


\section{$733 \quad$ Figure Legends}

734

Fig. 1 Plot positions overlayed on to a krigged plot of initial soil organic matter content determined in the top $0-10 \mathrm{~cm}$ layer on a $10 \times 10 \mathrm{~m}$ grid across the two fields of the BangorDIVERSE experimental site. In field 1 the gray overlay marks the approximate extend of the short rotation coppice trial. Coloured boxes represent plots of A. glutinosa (green), B. pendula (yellow) and $F$. sylvatica (blue) in monoculture, and a three species tree polyculture (orange), or a grassland (red).

Fig. 2 Vertical distribution of soil organic carbon from under monoculture or polyculture stands of B. pendula, A. glutinosa, and $F$. sylvatica, or a grassland. Symbols show means \pm SE $(n=3)$, statistically significant differences $(P<0.05)$ are denoted by a superscript asterisk.

Fig. 3 The contribution of fractions 1, 2 and the residual fraction 3 to the total $\mathrm{C}$ pool in different soil layers from under monoculture and a three species polyculture of $B$. pendula, A. glutinosa and $F$. sylvatica, or a grassland. Shown are means \pm SE ( $n=3)$, statistically significant differences are denoted by a superscript asterisk $(* \mathrm{P}<0.05, * * \mathrm{P}<0.01$ and $* * * \mathrm{P}<0.001)$.

Fig. 4 The total soil pool $\left(\mathrm{kg} \mathrm{C} \mathrm{m}^{-2}\right)$ of fraction 3 as determined by sequential acid extraction in a $1 \mathrm{~m}$ deep soil profile under B. pendula, A. glutinosa, $F$. 
sylvatica and grassland. Bars show means $\pm \mathrm{SE}(n=3)$. Bars not followed by similar indices are statistically significant $(P<0.05)$.

758

759 Fig. $5 \mathrm{C}$ fractions in leaves and roots of B. pendula, A. glutinosa, F. sylvatica and a grassland as determined by sequential acid hydrolysis. Values shown are expressed as the percentage of total C. Shown are means \pm SE $(n=4)$. Bars with same indices are not statistically significant $(P<0.05)$.

763

764 Suppl. Fig. 1 Relationships between clay content and (a) total soil organic C, (b) labile $\mathrm{C}$ fraction 1 and (c) recalcitrant $\mathrm{C}$ (fraction 3 ) for soils under monoculture and a three species polyculture of B. pendula, A. glutinosa and $F$. sylvatica, or a grassland. 